\title{
Sound as affect: difference, power and spatiality Michael Gallagher
}

This article is the 'author final' version of a paper that was published in the journal Emotion, Space and Society in 2016. The published version makes the same arguments, but includes a number of corrections and minor changes, as well as audio files. I would therefore recommend readers to use the published version, which is available at:

http://authors.elsevier.com/sd/article/S1755458616300196

If you do not have a subscription to the journal, please email me and I will send you a PDF version of the published article. My email address is m.gallagher@mmu.ac.uk, or your can look up my contact details on my website at www.michaelgallagher.co.uk 


\section{Abstract}

This article considers what happens when sound is understood as affect. It begins by recounting a minor event in which sound moved my body. I use this as a starting point for defining sonic affect as the vibrational movement of bodies of all kinds, moving away from anthropocentric notions of sound. The vibration of bodies can be understood as a 'base layer' of sound, which may activate or accrue layers of feeling and significance, but is not reducible to them.

Developing this conceptualisation of sonic affect, I argue that: (i) there are repeating affective tendencies of sound, but these unfold differently in context; (ii) sonic affect exercises power over bodies, sometimes by combining with sonic meaning; and (iii) sound propagates affect through space in distinctive ways, some of which I discuss. These arguments are grounded in numerous examples, reflecting the variety of both sound and affect. 


\section{Microphone trouble}

On a research trip to Berlin in 2013, I visited Nauenerplatz, a public square which had been redeveloped a few years earlier. Unusually, the redevelopment had involved attempts to improve the sonic environment, including audio benches that play back recordings of birdsong and breaking waves (Schulte-Fortkamp, 2011). Nauenerplatz is in Wedding, historically an area of economic poverty, with high unemployment, high ethnic diversity, and probably on the cusp of gentrification - a complex backdrop for a sonic intervention. As part of ongoing research on sound and space, I wanted to experience the square for myself and document it using audio recordings and photographs.

Much could be written about the production of space through the redevelopment of Nauenerplatz, the aesthetics, semiotics and politics of the new design, and its public reception. However, I want instead to recount a minor incident that unfolded as I was about to leave. Having spent half an hour or so exploring and recording in the square, a slight sense of something came over me. Skirting the very edge of awareness, I thought I could detect a subtle change of atmosphere; perhaps a hint of having outstayed my welcome, or maybe just paranoia. I looked around. The sun was shining, children were playing in the square, and there was nothing visible to confirm my unease.

Nevertheless, something didn't feel quite right, so I prepared to leave, packing up my recording equipment. I unplugged the furcovered windjammer encasing my microphones and set it down on a bench while I coiled up the cable. I could hear noisy clattering and shrieking nearby. Feeling slightly on edge, I looked over to see children riding around on pedal go-karts a little distance away, outside a youth centre in the square. 
I returned to sorting out my gear, but something in the situation was developing. I have a vague recollection of hearing a sound getting closer, and an internal bodily sensation that is hard to describe: a kind of movement, something welling up, like an electrical charge building. Suddenly my hand darted out and grabbed the microphone windjammer from the bench, lifting it into the air - just inches away from the outstretched grasp of a boy clattering past on a go-kart.

Only at this point did I realise what was going on. A child was trying to make off with my microphones, and somehow l'd managed to foil his game. A wave of relief mixed with panic came over me. Trying to diffuse the situation, I looked at the boy and smiled, but my face probably betrayed anxiety. I felt vulnerable, and also a bit ridiculous. The child looked to be no more than about 10 years old. He was laughing and speaking to me in German. I couldn't comprehend what he was saying, but I got the impression that he was being playful rather than malicious.

Again he reached out to grab the windjammer, and again I lifted it away. I was now acutely aware of being a foreigner, out of place naïve to the point of stupidity, wandering around an unfamiliar inner city location with conspicuous, odd-looking, expensive machines. Time to leave. I turned to make my exit, but as I stepped out of the square onto the adjoining pavement, the boy zipped around a corner, steered towards me, and crashed his kart into my feet, blocking my way and shouting. He was still laughing but his speech had turned into shouting and the atmosphere now felt tense. Spotting a gap in the traffic, I stepped sideways into the road and strode briskly across towards the nearby u-bahn station, relieved but embarrassed.

What stayed with me most from this episode was the experience of my hand reaching out unexpectedly, without any preconceived 
intention, and yet with such precision as to indicate a finely honed sense of what was going on in the space. How did my body know what to do? Perhaps something in the ambience of the square had primed me for possible conflict, through subtle aural cues of volatile energies building, something about to 'kick off'. What seems certain is that the sound of the rapidly approaching go kart moved my body, activating a sensory-motor coupling. The experience recalls Thrift's $(2008,7)$ description of affect as a "roiling mass of nerve volleys [which] prepare the body for action in such a way that intentions or decisions are made before the conscious self is even aware of them".

\section{Sound as affect}

The incident in Nauenerplatz might be considered unremarkable, just one of the many surprises of everyday life. However, I recount it as a starting point for exploring what happens when sound is understood as a form of affect. Sound is often referred to as activating feelings and emotions, and that clearly took place in Nauenerplatz, but I want to argue that sound itself is also a kind of affect - an oscillating difference, an intensity that moves bodies, a vibration physically pushing and pulling their material fabric.

Anderson argues that affect is not a single ontological force; instead, different conceptions of affect operate as sensitising devices, revealing different aspects of life. "The question of 'what is affect' gets replaced by questions of what the terms allow us to do: What do they attune to? What do they show up?" (Anderson, 2014, 12) Accordingly, this paper asks: what happens if we understand sound as affect? What does this conceptual filter allow us to hear?

Building on previous work in this area, I offer four answers. First, I suggest that understanding sound as affect strips back the discursive and socio-cultural layers of sound to begin analysis at a 
more basic level, with the vibrational movement of bodies. This movement is a 'base layer' of sound, which tends to accrue or entrain other layers - motor responses, feelings, perceptions, meanings, memories and so on - but which does not require these layers, and is thus not reducible to them (Gallagher, 2013). This is not to undermine the valuable insights that can be produced by studying other layers of sound; throughout this paper, my discussions of specific examples extend across a variety of different layers. Nevertheless, commencing analysis with the vibrational movement of bodies, and moving outwards from there, is useful as a way to decentre the human, positioning it as just one kind of body amongst many through which sound propagates. This conceptual filter enables analysis of how sound is sensed, felt and responded to by sentient beings, but also attunes to how sound moves the materialities of other kinds of bodies. At the same time, it avoids analysis becoming too fixated on materiality, since sound is understood as waves of movement through and between bodies.

Second, I suggest that it is possible to hear repeating sonic-affective tendencies, such as sudden loud sounds agitating bodies to make them jump or startle, but these are far from deterministic. Their repetition unfolds difference. Sonic affects cannot be guaranteed in advance. They arise in situ amongst multiple bodies and forces, often producing unexpected results. I examine auditory bird scaring devices and wind turbine noise as examples of this interplay.

Third, I argue that theorising sound as affect can help in understanding the exercise of neoliberal biopower. I consider two sonic technologies used to regulate public spaces: high frequency devices designed to disperse young people, and automated voice announcements. The announcements in particular demonstrate how affect and meaning can combine to produce effects of power. 
Finally, I address spatiality, making observations about how sound propagates affect through space in distinctive ways. This discussion partially addresses Pile's (2010) questions about the mechanisms by which affect is transmitted. Examples discussed include the spatiality of binaural hearing, the participation of bodies in relaying affect through school classrooms, the telephone as a technological transmitter of affect, and low frequency noise as an instance of the spatial politics of frequency.

I have chosen to ground my conceptualisation of sonic affect in these examples because both sound and affect are so varied that little can be said about them in general: "affects cannot be thought outside of an environmental or ecological context." (Ash, 2014, 2) I have tried to select disparate examples to evoke the sheer variety of sonic affects. Both sound and affect are always escaping, always on the move, and I have attempted to perform something of this incessant motion in the paper. Audio files and links are also provided to enable readers to hear renditions of some of the examples, in keeping with arguments I have made elsewhere for the expansion of phonographic research methods (Gallagher and Prior, 2014).

\section{Conceptualising sonic affect}

The conception of affect on which I draw throughout this paper follows an increasingly popular line of thinking from Spinoza through Deleuze and Guattari via Massumi, which defines affect as any process in which bodies affect, or are affected by, other bodies. It involves any kind of body impinging on another body in some way that augments or diminishes the affected body's capacities to act. We can think about how teachers affect students, how rain affects soil, or how food affects animals, for instance. Affects are often thought of as that which can be felt, but in this theorisation affects are forces that move bodies; these movements may or may not register as what could be called feelings. 
These ideas are not unproblematic (e.g. Leys, 2011), but they are useful in relation to sound because they draw attention to its propagation through bodies of many different kinds, both human and non-human. Sound has been theorised as relational, a force that connects bodies (LaBelle, 2010), but thinking of sound as affect goes further to recognise that "[s]ound does not just connect things; it changes them." (Kanngieser, 2015, 81) In acoustics, sound is understood as mechanical waves moving matter - a process of bodies being moved, changed, affected. There is no sound that does not affect bodies of some kind. Equally, bodies also affect sound. Their material characteristics modulate its amplitude, frequency spectrum, timing and so on, which in turn alters its capacities to affect other bodies.

A 'body' in this formulation "can in principle be anything" (Anderson, 2014, 9). Bodies may be human, but also intra-human, such as a cochlear affecting the auditory nerve, or extra-human, such as a body of air vibrating leaves. Recognising how sound affects many different kinds of bodies undermines anthropocentrism. Humans are just one possible element in vibrational assemblages, and in many cases may be marginal or absent. This conceptual move is important because sound is often heard through the filters of human language, music and auditory perception, to the exclusion of other sounds and forms of response. Acoustic ecology and sound art have all helped to raise awareness of how sound circulates amongst many different kinds of beings, materials and environments, across "registers that are unfamiliar, inaccessible, and maybe even monstrous; registers that are wholly indifferent to the play of human drama." (Kanngieser, 2015, 81) Understanding sonic affect as vibrational movement allows analysis to include bodies that would not normally be considered sentient: 
sub bass vibrating a drink in a nightclub, a rockfall reverberating from a cliff face, wind rattling windows.

These ideas chime with theories of hybrid culture-natures and new materialist political ecologies, which "horizontalize the relations between humans, biota, and abiota" (Bennett, 2010, 112). Understanding sound as affect pushes towards greater recognition of "sound's independence from the necessity of its being heard... suggesting a non-anthropic audition" in which sound "resonates with sets other than the ear." (Schrimshaw, 2013, 43) Faced with the famous riddle about whether a tree falling in a forest makes a sound if there is no-one around to hear it, this theorisation answers a decisive 'yes'. The resulting vibrations will move air, other plants and animals within the environment. Sound does not require the presence of human listeners. Admittedly, humans are likely to be particularly interested in sonic affects that produce sensations within human bodies, as in most of the examples I discuss in this paper. Nevertheless, even where humans are involved, sound always affects other kinds of bodies too.

Theories of affect describe how it flows between bodies, a movement variously characterised as circulation, transmission, contagion (Pile, 2010), travel and translation (Ash, 2014). With sound, this movement can be understood via acoustics, as the propagation of waves through and between bodies, resonating within them, reflecting off their surfaces, or being absorbed and dampened by them. This propagation goes beyond individual bodies, contributing to the atmosphere or ambience of a space (Anderson, 2009, McCormack, 2008, Thibaud, 2014). In Nauenerplatz, sonic affect propagated from an assemblage of boy and go-kart (legs, feet, pedals, wheels, tarmac), through a body of air, to affect an assemblage of man and microphones (ears, hand, arm, windjammer, bench), producing an atmosphere of tension. 
Massumi (1987) emphasises that affects are prepersonal intensities rather than personal feelings. Affects may be partially captured by subjectivity and representation, pinned down as nameable emotions, but they always exceed the fixing power of that capture. In Nauenerplatz, after the initial shock my cognition worked hard to make sense of what had happened, narrating what I had felt as emotions experienced by an indentifiable subject: I was anxious, I felt panic. But in the moment there was only an inexplicable sense of being caught up in movement.

Thien (2005) has critiqued this distinction between affect and emotion, arguing that it sidelines human feelings in favour of a distancing, masculinist worldview. Throughout the examples discussed in this paper, human emotions feature as important elements of sonic milieus. But starting analysis with emotions, rather than with the underlying vibrational movements, domesticates sound within the parameters of sentience. By recognising that "affect need not be felt...sound-affect need not be heard" (Schrimshaw, 2013, 41), it becomes possible to hear how sound circulates through any and every kind of body: from plants, animals, machines, objects and architectures, through to environments, atmospheres and the earth itself (e.g. Ganchrow. 2015).

A final related issue is the distinction between affect and meaning. Non-representational theory has critiqued the obsession in social sciences with interpreting meaning, shifting attention to how life happens through practices, performances and affects, whose perpetual motion is constantly slipping out of the grasp of representation (Thrift, 2008). These arguments do not suggest that meaning ought to be wholly excluded from the analysis of affect, but rather that attention needs to be paid to the push and pull between 
affect and meaning, examining how affects are represented and how representations produce affects (Anderson, 2014, Gallagher, 2015). Similarly, Revill (2015) suggests that sound involves the interplay of the phenomenology of listening, physical vibration in materials, and meanings, such that all three need to be considered simultaneously.

Whilst holding onto Revill's sense of sound's multiplicity, the conceptualisation I am setting out here is slightly different. Sonic affect, as the physical movement of bodies, can be understood as a 'base layer' of sound, which - to repeat - need not necessarily be perceived, felt or meaningful (Gallagher, 2013). On account of its lively motion, this base layer does tend to activate other registers as it encounters bodies, sparking nervous and motor systems, accruing or entraining additional layers of sense and signification. The task of a sonic-affective analysis is to begin with the vibration and work outwards from there. The hum of my domestic refrigerator, for instance, presumably drones away while I am sleeping or out at work, discharging energy into the surrounding environment in a way which does not 'mean' anything. When encountered by human bodies, however, the fridge hum may become soothing, reassuringly familiar, or it may provoke annoyance, perhaps feeding into understandings of power consumption, carbon footprints and climate change (Duffy and Waitt, 2013).

Thus depending on the bodies involved, what begins as a flow of raw vibration may produce sensations, emotions or moods, or push through into the realm of significance to be heard as anything from slight hints of something, evoked memories, associations or senses of space, through to more formal meanings and representations, as in spoken language. Sonic affects may accumulate layers of significance over time, through repetition and habit, by becoming attached to other affects: a young child praised by parents for 
mimicking the sounds of their language, a dog associating the jingle of its leash with the excitement of being taken out for a walk, or fishermen learning to feel conditions under the sea from the vibrations of a trawl net (McCall Howard, 2013). Much of what is heard in sound is too vague or idiosyncratic to be organised into semiotic systems, remaining closer to what Deleuze calls sense, summed up by Williams $(2008,33)$ as "forms of significance resistant to fact-based and meaning-based analysis". In Nauenerplatz, my body sensed the sound of the go-kart, and recognised that it signalled danger coming rapidly closer, but that 'meaning' was intuited in a flash, outside the conscious circuits of language, interpretation and representation.

The notion of sound as affect has already been put to work in various ways. Thompson and Biddle's (2013b) edited collection covers a range of topics, with a particular focus on music. Human geographers have attended to how sonic affect operates in everyday spaces, such as streets (Simpson, 2011), cafes (Boyd and Duffy, 2012) and homes (Anderson, 2004, Duffy and Waitt, 2013), and through the political force of voices (Kanngieser, 2012). Duffy and Waitt have developed a visceral conception of sound, drawing attention to its embodiment as gut feelings. In my own research on environmental audio practices such as field recording and audio walks, I have examined how such human-bodily affects arise in encounters with audio technologies and landscapes (Gallagher, 2014, 2015). Along similar lines, Ash (2014) has discussed tinnitus as an example of the sonic-affective force of technologies, arguing that the same sound can affect different bodies differently, and that sonic affect is not always fleeting but can leave lingering, even permanent traces. This life-changing potency of sonic affect is particularly apparent in the exercise of power through sonic torture and sonic warfare (e.g. Cusick, 2008, Goodman, 2009). 
The aim of this paper is to build on all of this previous work, using a range of examples to 'fill out' the conceptualisation of sonic affect. To this end, the remainder of the paper develops arguments concerning (i) the interplay of repeating affective tendencies and differences, (ii) sonic affects and the exercise of power, and (iii) the spatiality of sonic affects.

\section{Repetition and difference in sonic affect}

An enduring problem in theorising sound is its diversity. Attempts to make general statements often result in problematically ahistorical, essentialist claims about what sound 'is' and what it 'does' that do not stand up to critical scrutiny (Sterne, 2003). There are always counter examples. Sound constantly unfolds in difference, confounding expectations. Thompson and Biddle (2013a) illustrate this affective variability by recounting how commercial chart pop music with a marked lack of any politicized content or form nonetheless energised crowds at UK anti-government demonstrations in 2010-2011. The affects arose not from the music itself, but from its circulation within a particular context.

However, it is also possible to observe striking similarities in sonic affects across different bodies and spaces. For instance, in convivial social settings the sound of laughter tends to be contagious, inciting other bodies to laugh, something which has been observed in chimpanzees as well as in humans (Davila-Ross et al. , 2011). Likewise the structures of electronic dance music, played at high volume in club spaces, tend to incite people to move, "acting as an affective glue, bringing together dancing bodies" (Thompson and Biddle, 2013a, 11). Anyone who has had a good clubbing experience will know the feeling: being compelled to dance by music, whose force seems to produce uncontrollable bodily movement. DJs develop detailed knowledge of which techniques and tracks are most likely to achieve this, referred to by visceral terms such as 
drops, bangers and dancefloor destroyers. All of this suggests that it may be possible to identify certain sonic-affective tendencies, which are then modulated by specific bodies in specific contexts. This interplay can be understood through Anderson's $(2012,37)$ concept of the 'affective condition', which "does not slavishly determine action...[It] shapes and influences as atmospheres are taken up and reworked in lived experience". Following Deleuze (2004), another way to understand these tendencies is as repetitions that always unfold in difference, rather than as recurrences of the same affect.

Gas powered bird scarers are a good example of affective repetition and difference. Known as gas cannon or gas guns, they emit loud gunshot-type sounds to induce startle responses in birds, causing escape flight to disperse them from agricultural crops, aquaculture facilities, aerodromes and landfill sites (Lorimer, 2013). The gas gun is a technology of spatial control that not only generates affect as sensation but literally moves bodies, enlisting birds' sensor-motor systems to expel them from territory. A field recording can be heard in Russell Haswell's self-explanatorily titled Exceptionally loud propane gas cannon bird scarer, available online at http://youtu.be/GIIPEzsPM90 The affective tendency of loud transient sounds to make animal bodies startle or jump is evident in many other sonic techniques, such as a teacher's handclap to gain the attention of students, starter pistols in athletics, and car horns amidst traffic. The source of this tendency - whether due to evolution, learning or something else - is beside the point. The fact is that it is sufficiently widespread to be used in technologies of spatial control.

In context, however, the way this tendency plays out is more complicated. Gas guns are only effective when their position and schedule is varied regularly, otherwise birds quickly become habituated to the sound, reducing its affective potency (Bishop et al. 
, 2003). Over time, some birds even learn that the loud blasts signify a food source (Lorimer, 2013, 187) - an example of affect accruing meaning through repetition. Gas guns have also proved unintentionally effective at transmitting affects to humans and other animals. Internet forums contain angry reports of disrupted sleep, nervous dogs and frightened horses throwing their riders. These bodies appear less able to acclimatise than the birds, and campaign groups have sprung up calling for gas cannons to be banned. The affective force of the technology has galvanised an unexpected politics of resistance.

Another instance of sonic-affective variability can be found in the issue of wind turbine noise nuisance. Again, there is a repetition across different bodies and sites, with many accounts referring to amplitude modulation, described either as thumping or swishing sounds, as the main source of disturbance (Bowdler, 2008, Lee et al. , 2011). However, there are also inconsistencies. Sufferers often have neighbours or cohabitants who hear these sounds but do not find them intrusive, or do not even hear them, leading to speculation that there are subjective factors which make certain people unusually sensitive to the sounds. But there also seem to be extra-subjective contextual factors. Levels of annoyance appear lower amongst residents who enjoy financial benefits from the turbines (Pedersen et al. , 2009). Time of day plays a part too, with disturbances experienced most often at night, a time when other background noises are quieter, sufferers are trying to sleep (van den Berg, 2009), and atmospheric conditions leading to high wind shear are more likely, increasing the chance of higher noise levels (Bowdler, 2009). Affects of distress thus arise within complex assemblages of meteorology, turbine blades, air, diurnal patterns, psychosomatic predispositions, and the architecture and materials of domestic spaces. 
The following excerpt from a field recording of a wind farm at Harlock Hill, Cumbria, UK, exemplifies the challenge of understanding the issue.

[Insert audio: Harlock Hill wind farm]

Caption: Field recording of 500kW wind turbines at Harlock Hill wind farm, Cumbria, UK. Microphones: Sennheiser MKH30/40 mid side pair.

Field recordings are often heard as representations (see Gallagher, 2015). However, this recording was made in the daytime, outdoors, close to the turbines - a context that was convenient for recording, but not the sort of situation where nuisance usually occurs. Even if I had been able to record nuisance-causing sound, the nuisance could not be experienced when listening back to the recording in a different time and space, with easy control over start, stop and volume levels, and without the long-term repeat exposure that leads to most complaints. In this example, any suggestion that audio media can capture, reproduce, or represent the affects of noise is called into question. Noise nuisance arises from bodies encountering vibrations in context. The affects at stake here remain resolutely outside the recording. They are literally non-representable.

The problem of wind turbine noise is challenging precisely because of its context-specificity and non-representability. Noise control policies are premised on universalist assumptions, such as uniform noise dose-response relationships, which attempt to establish a sound pressure level below which any 'normal' person will not be affected, regardless of context. Legal requirements can then be set, and standardized measurements made to ensure that wind farms meet them. Acousticians at Arup have even produced software simulations of wind farm noise in an attempt to allay the fears of communities where developments are planned (Burgemeister, 
2013). Unfortunately, like my recording, these simulations miss out the all-important contextual factors. Such technocratic fantasies come unstuck in an emergent world, where disruptive affects arise spontaneously, at the accidental intersections of unpredictable bodies and forces. The mismatch between the universalist epistemology of noise control and the particularity of situated affects only serves to exacerbate conflicts. Wind energy firms and developers confidently claim that their installations comply with all relevant legislation and are therefore not noisy, while sufferers angrily point to their visceral experiences of sleep deprivation, illhealth and being driven to distraction by repetitive turbine sounds.

In summary, whilst it is possible to make claims about sonic affective tendencies, it is important to guard against determinism. It is not inevitable that a certain sound will generate a certain affect. Sonic affects also appear to be primarily contextual rather than subjective. They arise in situ, as vibrations and other non-acoustic forces impinge upon disparate collections of bodies, materials and technologies. Sonic affects repeat, but in a way that unfolds difference, with an element of instability, the possibility of subversion or unintended consequences. General claims about sonic affect therefore need to be checked out against specific empirical investigations.

\section{Affect and power}

If sound is understood as kinetic motion that affects bodies, shaping their capacities, it fits Foucault's definition of power as actions whose effect is to shape other actions (Foucault, 1983). Whilst Foucault famously wrote of how disciplinary power is exercised through technologies of visibility, sonic technologies are also widely used to regulate bodies and spaces. Examples include stethoscopic ascultation in medicine (Rice, 2013), surveillant listening in schools (Gallagher, 2010, Gallagher, 2011), the long history of 
eavesdropping (Zbikowski, 2002) and the growing use of audio recording to supplement CCTV technologies.

Goodman (2009) has argued for a politics of frequency, attuned to the affective force of extremely low and high frequencies. One example he discusses is the Mosquito device, a sonic technology used to discourage young people from loitering in public spaces. It generates high frequency buzzing that can produce discomfort within a range of around 40 metres, and which disproportionately affects the youthful. Younger people are typically more sensitive to high frequency sounds than older people, because the latter are affected by age-related hearing degeneration. As with the gas guns, Mosquitos produce vibrations designed to play on auditory physiology to exercise spatial power, circumscribing and policing territories. The device is controversial, and has been banned by a number of UK local authorities. However, in another example of the instability of sonic affect, some teenagers have appropriated the sound as a ring tone for their phones, nicknamed 'Teen Buzz', enabling them to message each other without being detected by adults. Examples can be heard - or not heard - in the Mosquito Audio Demo at http://www.movingsoundtech.com/ and the Mosquito Ringtones website at http://www.freemosquitoringtones.org/

The Mosquito sound began as a raw irritant, but was later repurposed as semiotic. In other instances, sound exercises power by simultaneously activating affective and semiotic registers. The voice is perhaps the best example of how affect and meaning are entangled in sound. As well as carrying messages in language, the sounds of voices move bodies: "not only the content but also the sounds of our speech have political consequences... The inflections and modulations of the voice contain forces that we must become more conscious of." (Kanngieser, 2012, 348) 
One example of such forces is the automated voice announcements increasingly used to regulate spaces such as railways stations, airports, supermarkets and vehicles. These technologies are explicitly positioned as affective tools of power: "designers can tap into the automatic and powerful responses elicited by all voices, whether of human or machine origin, to increase liking, trust, efficiency, learning, and even buying." (Nass and Brave, 2005, 4) The following short soundscape composition draws attention to some of the vibrational qualities, timbres and ambiences of these technologies.

Caption: A selection of automated voice announcements recorded in Edinburgh and Glasgow, UK. Microphones: DPA 4060 pair, spaced and binaural; Shoeps CMC641 mid-side pair. [Insert audio: automated voice announcements]

Automated voices have a notable gendered dimension. Nina Power (2013) claims that the majority of announcements in the UK use the affective qualities of the female voice to enforce neoliberal spatial politics. Where Haraway (1991) saw the cyborg as a figure of radical feminist possibility, female voice announcements are an altogether more docile woman-machine hybrid, whose de-sexualised, matronly manner invites subjects to comply, taking part in their own selfregulation and the safe management of risk. These voices attempt to manufacture an atmosphere of orderliness and obedience, playing on unconscious psychic traces in listeners of the motherly voice, the female nursery or primary school teacher's voice, the matriarchal voice. The result is a gentle-but-firm persuasiveness, an affective ambience designed to make for a more sympathetic reception of transport updates, security announcements, apologies for delays. These voices have thus become "a central asset in the continued securitisation and control of contemporary space, cutting across what little is left of the public realm and providing the 
appearance and the illusion of efficiency and calm in commercial environments." (Power, 2013, 37)

Returning to my arguments about difference, however, such affects are not guaranteed. The oddly disjointed intonation and timing of automated voice systems can be estranging. Their indifferent placidity may generate frustration or anger, while their monotonous ubiquity routinely creates boredom or ennui, producing insipid, bland atmospheres in which information is easy to ignore. Announcements often compete with ambient noise, making them inaudible or only semi-intelligible, as can be heard in the audio clip. In large spaces they become swamped in reverberation, lending them a semi-religious, cathedral-like, sombre mood that sits uneasily with the banality of their messages. Such affects can be self-satirising, as though the voice of God had been reduced to issuing warnings about slippery surfaces and apologising for any inconvenience caused.

\section{Sonic affect and space}

Sound propagates affect through space in distinctive ways. In this section I will attend to four aspects of sonic spatiality that have particular implications for affect: binaural hearing; participation; technology; and frequency.

One feature of the propagation of sound is that it moves sufficiently slowly that many animals are capable of using time delays to gauge the distance, direction and motion of sound sources. Binaural hearing - an auditory system with two ears spaced apart - enables the detection of differences in timing, intensity and frequency between vibrations moving one ear and the other. Animals can use these intra-aural differences to spatially locate sound sources and track their vectors of movement, all at a pre-cognitive level (Gilkey and Anderson, 1997). Thus binaurally equipped bodies use sonic 
affects, as vibrational movements, to develop a detailed preconscious sense of space, including an awareness of the locations of prey, surfaces, moving objects and so on. It is likely that binaural hearing was what enabled my body to sense the approaching gokart in Nauenerplatz without requiring conscious awareness.

The following recording demonstrates the principle. It was made beside a road using a binaural recording set up, with miniature microphones positioned close to my ears, thereby incorporating intra-aural differences and the acoustics of a human head into the recording. Another human body listening to the recording on good quality headphones should be able to sense the locations, directions and speeds of vehicles despite the absence of visual cues, provided there are no significant hearing impairments.

[Insert audio file: binaural recording of a road] Caption: Binaural recording of a road in central Edinburgh, UK. Microphones: DPA 4060 pair, in head mounted binaural position.

The propagation of sonic affects through space also relies on bodies as active participants. Think of how one dog can set off a chain reaction of barking across a neighbourhood, how applause ripples through a crowd, or the way that hammering sounds within plumbing can run long distances through pipes. Equally bodies can absorb or resist sounds, breaking the chain of affective contagion, as with soundproofing. One example of the relationship between participation, affective contagion and power is 'the countdown technique', a disciplinary 'game' I observed in an ethnographic study of a primary school (Gallagher, 2010, Gallagher, 2011). When a class was becoming noisy, one person, usually a teacher but sometimes a child, would initiate a verbal countdown to silence. The rule was that everyone else had to join in, chanting 'three, two, one, shhh!' and then becoming silent. The countdown used sound to 
regulate sound, attaching a function of spatial control to affects of fun and feelings of togetherness. It was contagious: part way through my fieldwork, I realised I had begun to join in habitually, without really being aware of it. The game did not always quieten children's bodies, but it was generally more effective than a simple verbal command to be quiet because it enrolled the children as participants in propagating sound through space. The teacher's voice alone did not carry well across a noisy classroom, but with the children's bodies enlisted as relays, sound could be more effectively transmitted.

Technological bodies also propagate sonic affects through space, as many of the examples discussed above make clear. Bull (2000) has written about the use of portable personal stereos to manage moods in urban space, but audio technologies can also propagate affect across large distances. Microphones, loudspeakers and radio were essential in Hitler's rise to power, transmitting affect to the masses through his voice (Kanngieser, 2012), while in Britain, Churchill's radio speeches boosted public morale, again with vocal tone playing a vital role (although Churchill may not have actually delivered them himself - see Thorpe, 2000). The popular film The Kings Speech presents itself as a personal narrative of a monarch overcoming a speech impediment, but could equally be interpreted as a political story, of a monarch shaping his sonic vibrations to align with the affective potential of radio for ruling.

The telephone is another technology for propagating sonic affect across space. Despite the efficiency of email and SMS text, the preconscious intensity generated by an almost-real-time rendition of a distant human voice remains powerful. From long distance relationships to customer services, from emergency services to negotiations between world leaders, from traditional landlines to Voice over IP, telephony is an exceptionally effective relay of sonic 
affect, despite its limited frequency bandwidth. With the development of mobile telephony and smartphones, the phone has infiltrated the public realm and extended its sonic repertoire. The result is a saturation of space with aural affects, such as the irritation of bystanders on hearing one side of a loud conversation, or the scratchy crackling of grime music being played by teenagers at the back of a bus.

Finally, the differential propagation of frequencies is an important aspect of the spatiality of sonic affect. Goodman's (2009) politics of frequency is necessarily a spatial politics, since low frequencies propagate through space more effectively than high frequencies, which are more easily blocked by bodies and materials. A notable example is low frequency noise, sometimes referred to as 'the hum'. Sufferers complain of disturbance by a persistent low pitched droning or rumbling sound, often likened to the idling of a diesel engine, which tends to be inaudible to most people, is difficult to register in recordings and noise measurements, and whose source cannot be traced (Leventhall, 2004). Its affective potency is considerable: "While only a relatively small number of people are affected, those who are tend to suffer severe distress...they may suffer various symptoms such as depression or even feel suicidal." (Moorhouse et al. , 2011, 2) Those who hear the hum often form geographic clusters, and report hearing it only within a particular locality. Audio recordings of low frequency noise can be auditioned online at http://bit.ly/1otPx8o High quality headphones or full range loudspeakers are recommended, otherwise the frequencies will be inaudible.

The current consensus amongst acousticians is that: (i) low frequency noise originates with environmental sources, such as vibration from heavy industry, heating or cooling systems, rather than being a purely perceptual phenomenon; (ii) these sounds are 
filtered by the atmosphere, the ground and the built environment, attenuating high and mid frequencies to leave a residue of low frequency, around the threshold of normal human hearing. It can propagate over considerable distances, and is more audible indoors due to the filtering effects of buildings; and (iii) noise complaints arise when individuals become unusually sensitised to these low frequency sounds (see Casella Stanger, 2001). Once again, there is a repeating affective tendency, of low frequencies to produce unease in sentient bodies, which becomes highly localised as difference unfolds from interactions between acoustics, materiality, environments, architecture, human physiology and subjectivity.

\section{Conclusions}

In this paper, affect has been used as a conceptual filter to understand sound as a force that physically moves bodies of many different kinds. This filter is useful because it enlarges upon anthropocentric conceptions of sound centred on language, music and emotion. The intention is not to exclude humans, but to position them as just one possible element in vibrational assemblages. Sonic affect, as the vibrational movement of bodies, can be understood as a base layer of sound which, due to its liveliness, often produces effects in other registers such as feeling, cognition, memory and meaning, but which also operates beneath and beyond these registers. I have suggested that the analysis of sonic affects might usefully begin with vibrational movement, and work outwards from there.

This paper has extended previous conceptions of sonic affective variation to theorise this as a repetition that unfolds difference. The general tendencies apparent in sonic affect are not the persistence of an underlying sameness, but a repetition that flexes and morphs in context, like a waveform mutating as it is fed through signal processing systems. Sweeping claims about sonic affects, such as 
that loud sounds produce fright or that low frequency sounds produce dread, need to be checked out empirically to see if they hold up in specific contexts.

The ability of sound to exercise power owes much to its affective potency, particularly when this operates in conjunction with conscious registers of sonic meaning. Research on power has produced many insights into how discursive practices, visual techniques and institutional structures regulate life, but there is scope for greater recognition of the ways in which sound, as an affective force, feeds into these processes.

Finally the paper has considered some of the ways in which sound propagates affect through space, suggesting that this process involves the affordances of binaural hearing, bodies participating as relays, electronic media technologies transmitting signals, and the differing spatialities of frequency. These observations are not exhaustive, but they begin to address Pile's (2010) questions about the mechanisms by which affect moves through space. He queries the ether that carries affects, but with sound there is nothing mysterious about this: it is matter, often air, sometimes solids or liquids. He also rejects metaphors of affect circulating in pipes and cables, preferring radio as a model. With sound, however, pipes, cables and radio all operate as actual media of affective transmission, not just as metaphors.

I have deliberately used a wide range of examples to demonstrate the variety of sonic affects. Sonic affects always happen within specific milieus, often unfolding in unexpected ways. They are ambivalent forces that can both enliven and alienate, soothe and intrude, repel bodies and attract them, regulate space and reconfigure it. 


\section{Acknowledgements}

Thanks to the UK Arts and Humanities Research Council for supporting the work on which this paper was based (grant AH/J006556/1). Thanks also to Anja Kanngieser, Peter Cusack, Claire Haggett and Hayden Lorimer, all of whom contributed to this work in different ways, and to the two anonymous reviewers for their constructive feedback.

\section{References}

Anderson B. "Recorded music and practices of remembering." Soc Cult Geogr 5 (2004): 3-20.

Anderson B. "Affective atmospheres." Emotion, Space and Society 2 (2009): 77-81.

Anderson B. "Affect and biopower: towards a politics of life." Transactions of the Institute of British Geographers 37 (2012): 2843.

Anderson B. Encountering affect : capacities, apparatuses, conditions. Farnham: Ashgate, 2014.

Ash J. "Technology and affect: Towards a theory of inorganically organised objects." Emotion, Space and Society (2014): http://dx.doi.org/10.1016/j.emospa.2013.12.017.

Bennett J. Vibrant Matter: A Political Ecology of Things. Durham and London: Duke University Press, 2010.

Bishop L, McKay H, Parrott D, Allan J. Review of international research literature regarding the effectiveness of auditory bird scaring techniques and potential alternatives. London: Defra, 2003. 
Bowdler D. Amplitude Modulation of Wind Turbine Noise. A Review of the Evidence. 2008.

Bowdler D. Wind shear and its effect on noise assessment of wind turbines. 2009.

Boyd C, Duffy M. "Sonic Geographies of Shifting Bodies." Interference (2012).

Bull M. Sounding out the city: personal stereos and the management of everyday life. Oxford: Berg, 2000.

Burgemeister K. Wind farms: hearing is believing. Arup, 2013.

Casella Stanger. Low Frequency Noise. Defra, 2001.

Cusick SG. "“You are in a place that is out of the world. . .": Music in the Detention Camps of the "Global War on Terror"." Journal of the Society for American Music 2 (2008): 1-26.

Davila-Ross M, Allcock B, Thomas C, Bard KA. "Aping expressions? Chimpanzees produce distinct laugh types when responding to laughter of others." Emotion (Washington, DC) 11 (2011): 1013-20.

Deleuze G. Difference and repetition. London: Continuum, 2004.

Duffy M, Waitt G. "Home sounds: experiential practices and performativities of hearing and listening." Soc Cult Geogr 14 (2013): 466-81. 
Foucault M. Afterword: the Subject and Power. In Michel Foucault: Beyond Structuralism and Hermeneutics, Edited by Dreyfus $\mathrm{H}$, Rabinow P, Chicago: Chicago University Press, 1983.

Foucault M. The Ethics of the Concern for Self as a Practice of Freedom. In Foucault Live, Edited by Lotringer S, New York: Semiotext(e), 1989.

Gallagher M. "Are schools panoptic?" Surveillance and Society 7 (2010): 262-72.

Gallagher M. "Sound, space and power in a primary school." Soc Cult Geogr 12 (2011): 47-61.

Gallagher M. Listening, Meaning and Power. In On Listening, Edited by Carlyle A, Lane C, Axminster, Devon: Uniformbooks, 2013.

Gallagher M. "Sounding ruins: reflections on the production of an 'audio drift'." Cultural Geographies (2014).

Gallagher M. "Field recording and the sounding of spaces." Environment and Planning D: Society and Space 33 (2015): 560-76.

Gallagher M, Prior J. "Sonic geographies: Exploring phonographic methods." Progress in Human Geography 38 (2014): 267-84.

Ganchrow R. On Long Wave Synthesis. In The Geologic Imagination, Edited by Altena A, Belina M, van der Velden L, Amsterdam: Sonic Acts Press, 2015. 
Gilkey RH, Anderson TR. Binaural and spatial hearing in real and virtual environments. Mahwah, N.J.: Lawrence Erlbaum Associates, 1997.

Goodman S. Sonic warfare : sound, affect, and the ecology of fear. Cambridge, Mass.: MIT Press, 2009.

Haraway DJ. Simians, cyborgs and women : the reinvention of nature. London: Free Association, 1991.

Kanngieser A. "A sonic geography of voice: Towards an affective politics." Progress in Human Geography 36 (2012): 336-53.

Kanngieser A. "Geopolitics and the Anthropocene: Five Propositions for Sound." GeoHumanities 1 (2015): 80-5.

LaBelle B. Acoustic territories : sound culture and everyday life. London: Continuum, 2010.

Lee S, Kim K, Choi W, Lee S. "Annoyance caused by amplitude modulation of wind turbine noise." Noise Control Engineering Journal 59 (2011): 38-46.

Leventhall HG. "Low frequency noise and annoyance." Noise Health 6 (2004): 59-72.

Leys R. "The Turn to Affect: A Critique." Critical Enquiry 37 (2011): 434-72.

Lorimer H. "Scaring Crows." Geographical Review 103 (2013): 17789. 
Massumi B. Notes on the Translation and Acknowledgments. In A Thousand Plateaus: Capitalism and Schizophrenia, Minneapolis: University of Minnesota Press, 1987.

McCall Howard P. Feeling the Ground: Vibration, Listening, Sounding at Sea. In On Listening, Edited by Carlyle A, Lane C, Axminster, Devon: Uniformbooks, 2013.

McCormack DP. "Engineering affective atmospheres on the moving geographies of the 1897 Andrée expedition." Cultural Geographies 15 (2008): 413-30.

Moorhouse A, Waddington D, Adams M. Procedure for the assessment of low frequency noise complaints. Salford: University of Salford, Manchester, 2011.

Nass $\mathrm{Cl}$, Brave S. Wired for speech : how voice activates and advances the human-computer relationship. Cambridge, Mass.: MIT Press, 2005.

Pedersen E, van den Berg F, Bakker R, Bouma J. "Response to noise from modern wind farms in The Netherlands." The Journal of the Acoustical Society of America 126 (2009): 634-43.

Pile S. "Emotions and affect in recent human geography." Transactions of the Institute of British Geographers 35 (2010): 5-20.

Power N. "Cyborg manifestos." The Wire 352 (2013): 37.

Revill G. "How is space made in sound? Spatial mediation, critical phenomenology and the political agency of sound." Progress in Human Geography (2015). 
Rice T. Hearing and the Hospital. Sound, listening, knowledge and experience. Canon Pyon: Sean Kingston Publishing, 2013.

Schrimshaw W. Non-cochlear sound: On affect and exteriority. In Sound, music, affect : theorizing sonic experience, Edited by Thompson M, Biddle ID, New York: Bloomsbury Academic, 2013.

Schulte-Fortkamp B. Soundscape approaches - public space perception and enhancement drawing on experience - Nauener Platz in Berlin. In COST Brighton Soundscape Workshop 2011, Brighton, UK, 2011.

Simpson P. "Street Performance and the City: Public Space, Sociality, and Intervening in the Everyday." Space and Culture 14 (2011): 41530 .

Sterne J. The audible past : cultural origins of sound reproduction. Durham, N.C. ; London: Duke University Press, 2003.

Thibaud J-P. "The backstage of urban ambiances: When atmospheres pervade everyday experience." Emotion, Space and Society (2014).

Thien D. "After or beyond feeling? A consideration of affect and emotion in geography." Area 37 (2005): 450-4.

Thompson M, Biddle ID. Introduction: Somewhere between the signifying and the sublime. In Sound, music, affect : theorizing sonic experience, Edited by Thompson M, Biddle ID, New York: Bloomsbury Academic, 2013a.

Thompson M, Biddle ID. Sound, music, affect : theorizing sonic experience. New York: Bloomsbury Academic, 2013b. 
Thorpe V. Finest hour for actor who was Churchill's radio voice. Recording proves who really made those war speeches. In The Observer, London: Guardian News and Media Ltd, 2000.

Thrift NJ. Non-representational theory : space, politics, affect. Abingdon and New York: Routledge, 2008.

van den Berg F. "Wind turbines: Why they are noisy and what to do about it." The Journal of the Acoustical Society of America 125 (2009): 2623.

Williams J. Gilles Deleuze's Logic of sense : a critical introduction and guide. Edinburgh: Edinburgh University Press, 2008.

Zbikowski D. The Listening Ear: Phenomena of Acoustic Surveillance. In CTRL [SPACE] Rhetorics of Surveillance from Bentham to Big Brother, Edited by Levin TY, Frohne U, Weibel P, Cambridge, MA and London: MIT Press, 2002. 